\title{
Application of ORC power station to increase electric power of gas compression ignition engine
}

\author{
Szymon Mocarski ${ }^{1}$, Aleksandra Borsukiewicz-Gozdur ${ }^{1, *}$ \\ ${ }^{1}$ Zachodniopomorski Uniwersytet Technologiczny w Szczecinie, Katedra Techniki Cieplnej al. Piastów 17, 70-310 Szczecin, Polska
}

\begin{abstract}
The paper presents the calculation results of efficiency of the subcritical low temperature ORC power station powered by waste heat resulting from the process of cooling a stationary compression ignition engine. The source of heat to supply the ORC power station is the heat in a form of water jet cooling the engine at a temperature of $92^{\circ} \mathrm{C}$, and the exhaust gas stream at a temperature of $420^{\circ} \mathrm{C}$. The study considers three variants of systems with the ORC power stations with different ways of using heat source. The first variant assumes using just engine cooling water to power the ORC station. In the second variant the ORC system is powered solely by a heat flux from the combustion gases by means of an intermediary medium thermal oil, while the third variant provides the simultaneous management of both heat fluxes to heat the water stream as a source of power supply to the ORC station. The calculations were made for the eight working media belonging both to groups of so-called dry media (R218, R1234yf, R227ea) and wet media (R32, R161, R152a, R134a, R22).
\end{abstract}

\section{Symbols}

$\mathrm{cp}$ - average heat capacity $[\mathrm{kJ} /(\mathrm{kg} \cdot \mathrm{K})]$

$\mathrm{h}$ - specific enthalpy $[\mathrm{kJ} / \mathrm{kg}]$

$\dot{\mathrm{m}}$-mass flow of the substance $[\mathrm{kg} / \mathrm{s}]$

$\mathrm{N}$ - power $[\mathrm{kW}]$

$\dot{\mathrm{Q}}$ - heat flux [kW]

$\mathrm{S}-$ specific entropy $[\mathrm{kJ} /(\mathrm{kg} \cdot \mathrm{K})]$

$\mathrm{T}, \mathrm{t}$ - temperature $\left[{ }^{\circ} \mathrm{C}\right]$

$\eta$ - efficiency [\%]

$\mathrm{X}-$ steam dryness degree $[-]$

subscripts:

$\mathrm{C}-\mathrm{R}$ - refers to Clausius Rankine cycle,

$\mathrm{c}-$ refers to medium cooling the condenser,

$\mathrm{d}-$ refers to supplied stream,

$\mathrm{g}$ - refers to exhaust gases,

$\mathrm{n}$ - refers to working liquid,

o- refers to thermal oil,

$\mathrm{p}$ - refers to pump,

par - refers to turbine inlet steam,

$\mathrm{s}$ - refers to water as a heat carrier,

$\mathrm{t}$ - refers to turbine,

wyp - refers to output stream,

$1,2,2 \mathrm{~s}, 3,4 \mathrm{~s}, 5,6$ - characteristic points of the cycle.

abbreviations in figures:

$\mathrm{G}$ - generator,

$\mathrm{P}$ - pump,

PWC - intermediary heat exchanger,

$\mathrm{S}$ - condenser,

$\mathrm{SW}$ - compression ignition engine,

$\mathrm{T}$ - turbine,

$\mathrm{WP}$ - steam generator,

$\mathrm{W} 1$ - heater,

W2 - evaporator,
W3 - superheater,

\section{Introduction}

Waste energy, due to its low fuel prices, for many years was not considered as a potential source of driving energy for further processes. The reason for this was the lack of concept/technology enabling efficient management of waste energy, or lack of economic justification for the investment in energy management systems. At the moment, significant reversal of this trend can be observable, and the example for this may be the release of relevant legal acts on this issue [1]. Unfortunately, the implementation of low and medium temperature energy conversion processes is usually featured by not very high thermal efficiencies. Waste heat recovery is theoretically possible everywhere where such heat is produced. Effective use of waste energy, and thus, maximizing the overall efficiency of all the processes of energy exploitation, production and conversion, in the age of increasingly higher awareness of the environmental care, depletion of conventional energy resources and financial benefits out of efficient use of energy should be a priority for modern energy and modern industry. For this reason, reducing the consumption of fossil fuels in the production of useful energy is now a serious challenge and is not only a research but also geopolitical goal. This is important due to the overall increase in energy consumption in the world and the resulting increase in emissions to the environment. One of the ways enabling, partially, to achieve this goal is to use the ORC power stations, which in many cases allow to manage low and/or 
medium temperature energy and effectively reduce or even eliminate a part of the energy loss to the environment. Using this type of energy in some other way could be difficult or impossible. The ORC stations allow for emission-free electricity production using geothermal, solar sources of energy, exhaust waste heat utilization or other medium at an increased temperature. An interesting idea might be the use of the ORC station as a secondary cycle, cooperating with a power station fed from a high temperature source, in order to increase the overall efficiency of the process. Another way to use the ORC station for waste heat management to increase the overall efficiency of the primary process is utilization of waste heat produced during combustion of gas fuel by a stationary compression ignition engine. Such an engine, working with an electric generator, creates a thermal-current set. The ways of using waste heat arising during the operation of the compression ignition engine to increase the efficiency of the electric generator set have been analyzed in papers [2] and [3]. This paper presents the calculation results for the compression ignition engine and the ORC station system while it was assumed that installation (adding a module) of the ORC does not interfere in the construction and operation of the compression ignition engine in any way, which means that it can be installed on already working engines. It was furthermore assumed that the ORC system is a system operating at relatively low temperatures. This assumption stems from the fact that the offer of low-temperature ORC stations is relatively rich at the moment because in systems of this type screw expanders (instead of turbines) may be used $[4,5]$.

\section{Analysis of using waste heat generated by compression ignition engine to power the ORC station}

The paper analyzes the possibility of using waste heat generated during the operation of the stationary compression ignition engine burning gaseous fuel. Mechanical power generated by such an engine is used to drive an electric generator in order to produce electricity. The efficiency of generating electrical power by such engines is relatively high (for modern engines up to $45 \%$ [1]) however, there is still thermal power in a form of a water jet cooling the engine and a stream of combustion gases emitted as waste heat. The paper analyzes the effectiveness of three variants to use this heat to power the ORC station in order to increase electric efficiency of the primary process carried out by the generator set. The analysis is based on the consideration of a possible use of both of these heat fluxes and determining to what extent the use of the ORC system improves the electric efficiency of the primary process. The analysis was carried out for eight different substances used as working medium in the ORC station, whose basic parameters are presented in Table 1.

The analysis examined the use of the ORC station operation according to the Clausius Rankine comparative subcritical cycle. A diagram of the ORC station, stating the basic elements of the system and the characteristic points of the cycle is shown in Figure 1a.

Table 1. Basic properties of working medium selected for analysis

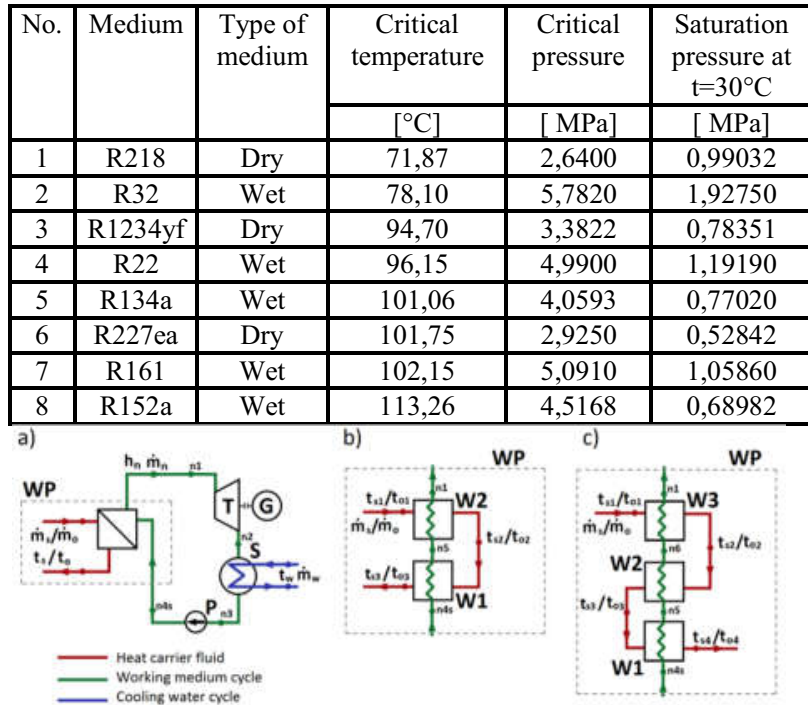

Fig. 1. Diagram of the ORC system a) and: the flow of fluid through steam generator exchangers using a dry medium $b$ ) and wet medium c).

A very important aspect of the discussion on the operation effectiveness of the ORC station is the shape of saturation curves of working media in the T-s system presented in Figure 2 because depending on what kind of working medium is examined, the operation of the station changes and results from the various solutions of the steam generator (WP), which entails differences in the way of determining the parameters of the working medium state and within the performed calculations.

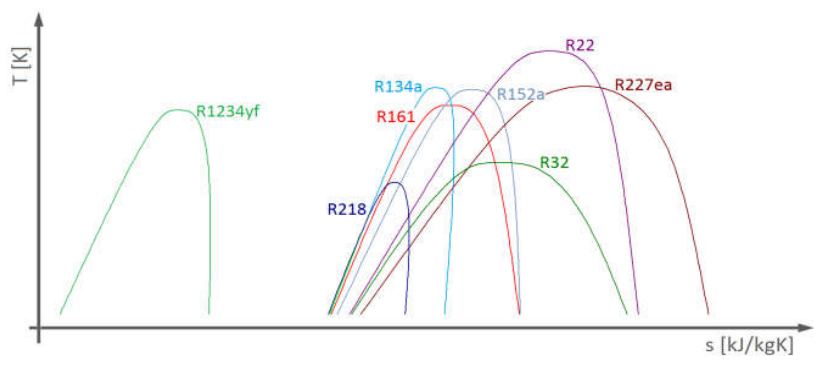

Fig. 2. Shapes of saturation curves of working media taken for analysis.

In case of using the dry medium the steam generator consists of two heat exchangers: the heater (W1) and the evaporator (W2) as shown in Figure 1b. While in the case of using the wet medium the steam generator needs to be supplemented with the third exchanger, the superheater (W3), in which the steam superheating takes place, as shown in Figure 1c. The heat source for the ORC station in this case is the DEUTZ POWERSYSTEMS TBG 620 V12K compression ignition engine adapted to burn gaseous fuel in the form of natural gas. The operating parameters necessary to treat the engine as a heat source for the ORC station are shown in Table 2. 
Table 2. Quantities characterizing heat source

\begin{tabular}{|l|l|l|}
\hline Quantity & Unit & Value \\
\hline Heat flux absorbed with fuel & {$[\mathrm{kW}]$} & 2592 \\
\hline Mechanical power of the engine & {$[\mathrm{kW}]$} & 1050 \\
\hline Mechanical efficiency of the engine & {$[\%]$} & 40,5 \\
\hline $\begin{array}{l}\text { Efficiency of the electric generator } \\
\text { (by the engine manufacturer) }\end{array}$ & {$[\%]$} & 96,2 \\
\hline $\begin{array}{l}\text { Electric power of the generator set } \\
\text { (after taking into account the efficiency } \\
\text { of the generator) }\end{array}$ & {$[\mathrm{kW}]$} & 1010 \\
\hline Electric efficiency of the generator set & {$[\%]$} & 39,0 \\
\hline Thermal efficiency of the engine & {$[\%]$} & 47,2 \\
\hline $\begin{array}{l}\text { Temperature of the engine cooling } \\
\text { water at the inlet }\end{array}$ & {$\left[{ }^{\circ} \mathrm{C}\right]$} & 78 \\
\hline $\begin{array}{l}\text { Temperature of the engine cooling } \\
\text { water at the outlet }\end{array}$ & {$\left[{ }^{\circ} \mathrm{C}\right]$} & 92 \\
\hline Heat flux carried by cooling water & {$[\mathrm{kW}]$} & 690 \\
\hline Flow rate of the engine cooling water & {$[\mathrm{m} 3 / \mathrm{h}]$} & $36-56$ \\
\hline $\begin{array}{l}\text { Mean specific heat of water } \\
\text { Exhaust gas temperature at the outlet of } \\
\text { the collector }\end{array}$ & {$[\mathrm{kJ} / \mathrm{kg} \cdot \mathrm{K}]$} & 4,19 \\
\hline $\begin{array}{l}\text { Exhaust gas temperature after having } \\
\text { used }\end{array}$ & {$\left[{ }^{\circ} \mathrm{C}\right]$} & 420 \\
\hline $\begin{array}{l}\text { Heat flux carried by exhaust gas } \\
\text { Flow rate of exhaust gas }\end{array}$ & {$[\mathrm{kW}]$} & 120 \\
\hline $\begin{array}{l}\text { Unusable power }(e n e r g y ~ l o s s) \\
\text { Mean specific heat of oil heat carrier }\end{array}$ & {$[\mathrm{kg} / \mathrm{h}]$} & 532 \\
\hline & {$[\mathrm{kW} / \mathrm{kgK}]$} & 2,70 \\
\hline & & 320 \\
\hline
\end{tabular}

In case of this engine the thermal power, that is available flux of waste heat possible to manage, is $47,2 \%$ of the total power supplied to the engine with the fuel. This power is transferred in an amount of: $690 \mathrm{~kW}$ carried along with the engine cooling water and $532 \mathrm{~kW}$ carried with the stream of combustion gases. Mechanical power of the engine is $1050 \mathrm{~kW}$, which represents $40,5 \%$ of the power supplied from the fuel while the electric efficiency of the primary process is $39,0 \%$. The remaining part of the energy flow supplied with the fuel are the losses of $320 \mathrm{~kW}$. The study contains analysis of three possible variants of using both heat flux to supply the ORC power station in order to increase the total electric power.

Variant I assumes that the source of power supply to the steam generator of the ORC system is only a heat flux of the compression ignition engine cooling water. A method of the heat input from the engine to the ORC station is shown in Figure 3.

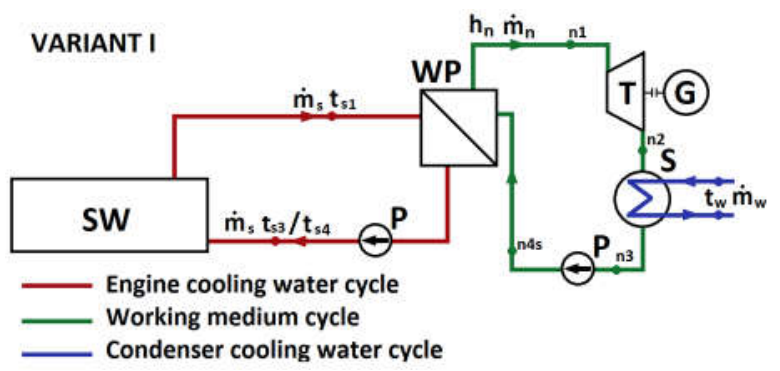

Fig 3. Diagram of ORC station supply in Variant I of using the heat source

This option implies the direct use of cooling water with the temperature of $92^{\circ} \mathrm{C}$ to power the ORC station without using intermediary heat exchanger and intermediary liquid, and such a design of the power station and heat exchanger WP that water after leaving the steam generator of the station had a temperature of $\mathrm{t}_{\mathrm{s} 3} / \mathrm{t}_{\mathrm{s} 4}=78^{\circ} \mathrm{C}$, that is the temperature at the inlet to the engine cooling system given be the engine manufacturer. Assuming that the minimum possible value of the temperature difference between the factors in the heat exchangers is at $\Delta \mathrm{t}=5 \mathrm{~K}$, the steam temperature of the working medium at the inlet of the turbine will amount maximum at $\mathrm{t}_{\mathrm{par}}=87^{\circ} \mathrm{C}$.

All assumed and calculated temperature values of individual characteristic points of the heat input from the heat source to the ORC station for variant I are given in Table 3 .

Table 3. Water temperature as heat carrier in individual characteristic points of the heat supply for variant I

\begin{tabular}{|l|l|l|l|l|l|}
\hline Medium & $\mathrm{t}_{\mathrm{s} 1}$ & $\mathrm{t}_{\mathrm{s} 2}$ & $\mathrm{t}_{\mathrm{s} 3}$ & $\mathrm{t}_{\mathrm{s} 4}$ & $\mathrm{~m}_{\mathrm{s}}$ \\
\hline & {$\left[{ }^{\circ} \mathrm{C}\right]$} & {$\left[{ }^{\circ} \mathrm{C}\right]$} & {$\left[{ }^{\circ} \mathrm{C}\right]$} & {$\left[{ }^{\circ} \mathrm{C}\right]$} & {$[\mathrm{kg} / \mathrm{s}]$} \\
\hline R218 & 92,00 & 84,58 & 78,00 & & 11,763 \\
\hline R32 & 92,00 & 85,97 & 84,63 & 78,00 & 11,763 \\
\hline R1234yf & 92,00 & 84,16 & 78,00 & & 11,763 \\
\hline R22 & 92,00 & 90,17 & 82,62 & 78,00 & 11,763 \\
\hline R134a & 92,00 & 91,32 & 83,41 & 78,00 & 11,763 \\
\hline R227ea & 92,00 & 84,70 & 78,00 & & 11,763 \\
\hline R161 & 92,00 & 90,56 & 82,19 & 78,00 & 11,763 \\
\hline R152a & 92,00 & 91,07 & 82,16 & 78,00 & 11,763 \\
\hline
\end{tabular}

Variant II assumes using exhaust gas energy to power the steam generator of the station through the use of intermediary heat exchanger in which the exhaust stream transfers heat to the intermediary oil circuit supplying the steam generator of the steam power station. A diagram of such a solution is shown in Figure 4.

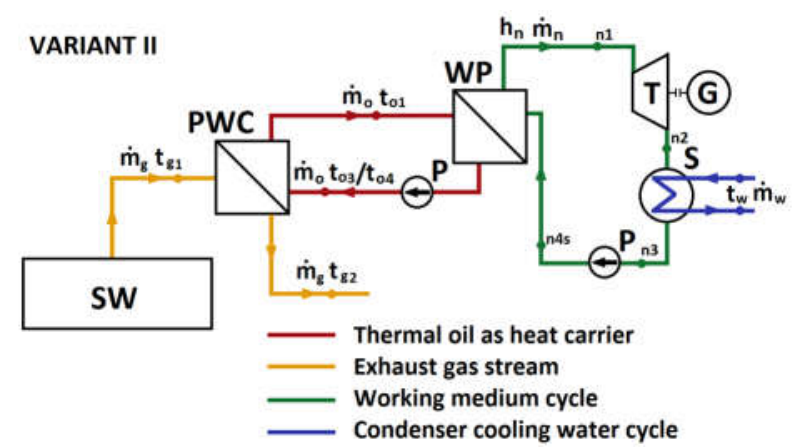

Fig. 4. Diagram of ORC station supply in Variant II with the use of exhaust gas energy as heat source

It was assumed that in order to obtain the heat flux of $532 \mathrm{~kW}$ from exhaust gases the exhaust gases must be cooled to a temperature of $\mathrm{tg}_{\mathrm{g} 2}=120^{\circ} \mathrm{C}$. It was also implied that the ORC cycle in variant II is a lowtemperature circuit and the temperature of the oil heat carrier at the inlet to the steam generator will amount $\mathrm{t}_{\mathrm{ol}}=115^{\circ} \mathrm{C}$. That in turn determines the maximum possible steam temperature value of working medium at the inlet to the turbine at $\mathrm{t}_{\mathrm{par}}=110^{\circ} \mathrm{C}$.

All assumed and calculated temperature values of individual characteristic points of the heat input from the heat source to the ORC station for variant II are given in Table 4. 
Table 4. Temperatures of oil heat carrier in individual characteristic points of the heat supply system for variant II

\begin{tabular}{|c|c|c|c|c|c|}
\hline Medium & $t_{01}$ & $t_{02}$ & $t_{0} 3$ & $t_{04}$ & $\dot{\mathrm{m}}_{\mathrm{o}}$ \\
\hline & {$\left[{ }^{\circ} \mathrm{C}\right]$} & {$\left[{ }^{\circ} \mathrm{C}\right]$} & {$\left[{ }^{\circ} \mathrm{C}\right]$} & {$\left[{ }^{\circ} \mathrm{C}\right]$} & {$[\mathrm{kg} / \mathrm{s}]$} \\
\hline R218 & 115,00 & 95,40 & 78,00 & & 3,432 \\
\hline $\mathrm{R} 32$ & 115,00 & 99,06 & 95,52 & 78,00 & 3,432 \\
\hline R1234yf & 115,00 & 95,41 & 80,00 & & 3,628 \\
\hline $\mathrm{R} 22$ & 115,00 & 108,04 & 93,41 & 78,00 & 3,432 \\
\hline $\mathrm{R} 134 \mathrm{a}$ & 115,00 & 109,79 & 105,20 & 88,00 & 4,703 \\
\hline R227ea & 115,00 & 99,78 & 78,00 & & 3,432 \\
\hline R161 & 115,00 & 111,59 & 103,84 & 96,00 & 6,683 \\
\hline R152a & 115,00 & 112,06 & 99,11 & 88,00 & 4,703 \\
\hline
\end{tabular}

Variant III involves the simultaneous use of both heat fluxes by heating the cooling water jet before referring it to the steam generator of the steam power station using the exhaust stream. A diagram of such a solution is presented in Figure 5.

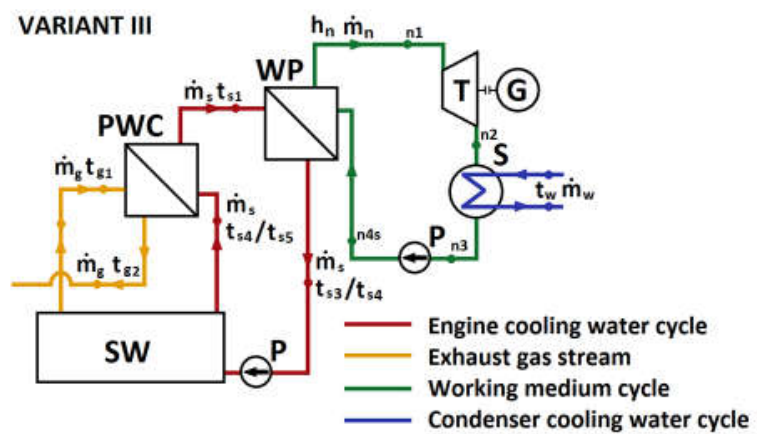

Fig. 5. Diagram of the ORC station supply in Variant III of using the heat source

In case of such a solution the maximum value of the evaporation temperature of working medium also depends on the temperature of the heat carrier at the inlet of the steam generator $t_{s 1}$, however here the value of the temperature should be determined on the basis of the energy balance equations of components included in the circuit of engine cooling water, which is a heat carrier from the heat source to the steam generator of the steam power station, too. In case of this engine and the parameters given by the engine manufacturer, which are contained in Table 1, the water temperature at the inlet of the steam generator is $t_{s 1}=102,8^{\circ} \mathrm{C}$, thus, taking into account the condition that the minimum temperature difference between the factors in the heat exchangers is $\Delta \mathrm{t}=5 \mathrm{~K}$, the maximum obtainable steam temperature of working medium at the inlet to the turbine in this variant amounts $\mathrm{t}_{\text {par }}=97,8^{\circ} \mathrm{C}$.

All assumed and calculated temperature values of individual characteristic points of the heat input from the heat source to the ORC station for variant III are given in Table 5.

Tables $3-5$ also give the values of the mass flow of the heat carrier in the heat supply circuit, depending on the variant of a heat source because in the case of variants I and III it is important to determine the mass flow of the engine cooling water which is at the same time the energy carrier in the circuit $\dot{\mathrm{m}}_{\mathrm{s}}$, as the size of this flux must be within the size range specified by the engine manufacturer, which is $36-56 \mathrm{~m}^{3} / \mathrm{h}$.

Table 5. Temperatures of water as the heat carrier in individual characteristic points of the heat supply system for variant III

\begin{tabular}{|c|l|r|l|l|l|}
\hline Medium & $\mathrm{t}_{\mathrm{s} 1}$ & \multicolumn{1}{|l|}{$\mathrm{t}_{\mathrm{s} 2}$} & \multicolumn{1}{|l|}{$\mathrm{t}_{\mathrm{s}}$} & $\mathrm{t}_{\mathrm{s} 4}$ & $\dot{\mathrm{m}}_{\mathrm{s}}$ \\
\hline & {$\left[{ }^{\circ} \mathrm{C}\right]$} & {$\left[{ }^{\circ} \mathrm{C}\right]$} & {$\left[{ }^{\circ} \mathrm{C}\right]$} & {$\left[{ }^{\circ} \mathrm{C}\right]$} & {$[\mathrm{kg} / \mathrm{s}]$} \\
\hline $\mathrm{R} 218$ & 102,80 & 89,66 & 78,00 & & 11,760 \\
\hline $\mathrm{R} 32$ & 102,80 & 92,12 & 89,74 & 78,00 & 11,760 \\
\hline $\mathrm{R} 1234 y f$ & 102,80 & 88,92 & 78,00 & & 11,760 \\
\hline $\mathrm{R} 22$ & 102,80 & 98,94 & 87,19 & 78,00 & 11,760 \\
\hline $\mathrm{R} 134 \mathrm{a}$ & 102,80 & 101,27 & 88,67 & 78,00 & 11,760 \\
\hline $\mathrm{R} 227 \mathrm{ea}$ & 102,80 & 92,01 & 78,00 & & 11,760 \\
\hline $\mathrm{R} 161$ & 102,80 & 99,88 & 86,11 & 78,00 & 11,760 \\
\hline $\mathrm{R} 152 \mathrm{a}$ & 102,80 & 100,95 & 86,01 & 78,00 & 11,760 \\
\hline
\end{tabular}

Calculation methodology is based on the energy balance equation of individual elements of the station scheme and the power system, on the assumption that the energy losses during heat transfer are negligible. The energy balance equations use the specific enthalpy values of working medium in the individual characteristic points of the system. The values of specific enthalpy were determined through the database of thermodynamic properties of the working media, REFPROP version 9.0 [6], taking into account the characteristics of the Clausius Rankine cycle and dependencies between the key parameters of the factor state such as temperature, pressure, specific enthalpy and specific entropy, resulting from the specificity of the Clausius Rankine cycle.

The course of thermodynamic processes of the Clausius Rankine cycle, according to which the parameters of working medium in the individual points of the station have been designated, is shown schematically in Figure $6 a)$ in the case of using wet medium and 6b) in the case of dry medium.

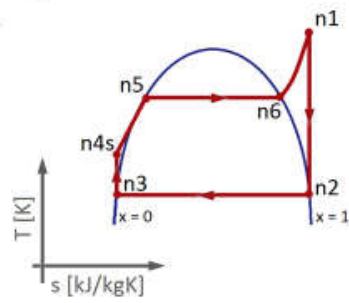

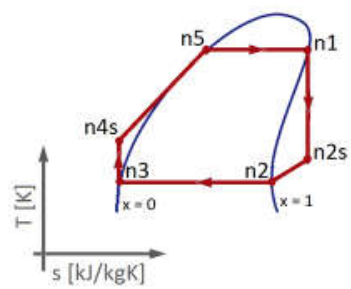

Fig. 6. Thermodynamic processes of Clausius Rankine subcritical cycle using wet medium a) and dry medium b)

Specific enthalpy values for individual variants of using heat source with corresponding temperature values are given in the table 6 .

It should be noted that Table 6 shows only the specific enthalpy values at a steam temperature at the inlet to the turbine $\mathrm{tn} 1$, at which it was possible to obtain the most advantageous operating parameters of the ORC station for the particular working medium. 
Table 6. Results of specific enthalpy values and temperatures in characteristic points of the ORC cycle

\begin{tabular}{|c|c|c|c|c|c|c|c|c|c|c|c|c|c|c|}
\hline Medium & $\mathrm{h}_{\mathrm{n} 1}$ & $\mathrm{t}_{\mathrm{n} 1}$ & $\mathrm{~h}_{\mathrm{n} 2}$ & $\mathrm{t}_{\mathrm{n} 2}$ & $\mathrm{~h}_{\mathrm{n} 2 \mathrm{~s}}$ & $t_{n 2 s}$ & $\mathrm{~h}_{\mathrm{n} 3}$ & $t_{n 3}$ & $h_{n 4 s}$ & $t_{n 4 s}$ & $\mathrm{~h}_{\mathrm{n} 5}$ & $t_{n 5}$ & $\mathrm{~h}_{\mathrm{n} 6}$ & $\mathrm{t}_{\mathrm{n} 6}$ \\
\hline & {$[\mathrm{kJ} / \mathrm{kgK}]$} & {$\left[{ }^{\circ} \mathrm{C}\right]$} & {$[\mathrm{kJ} / \mathrm{kgK}]$} & {$\left[{ }^{\circ} \mathrm{C}\right]$} & {$[\mathrm{kJ} / \mathrm{kgK}]$} & {$\left[{ }^{\circ} \mathrm{C}\right]$} & {$[\mathrm{kJ} / \mathrm{kgK}]$} & {$\left[{ }^{\circ} \mathrm{C}\right]$} & {$[\mathrm{kJ} / \mathrm{kgK}]$} & {$\left[{ }^{\circ} \mathrm{C}\right]$} & {$[\mathrm{kJ} / \mathrm{kgK}]$} & {$\left[{ }^{\circ} \mathrm{C}\right]$} & {$[\mathrm{kJ} / \mathrm{kgK}]$} & {$\left[{ }^{\circ} \mathrm{C}\right]$} \\
\hline \multicolumn{15}{|c|}{ VARIANT I } \\
\hline R218 & 316,96 & 60,00 & 306,53 & \multirow{8}{*}{30,00} & 310,29 & 33,77 & 233,84 & \multirow{8}{*}{30,00} & 234,64 & 31,02 & 273,35 & 60,00 & & \\
\hline R32 & 557,19 & 108,83 & 515,72 & & & & 255,32 & & 259,39 & 33,00 & 400,38 & 78,00 & 428,90 & 78,00 \\
\hline R1234yf & 235,71 & 75,00 & 218,33 & & 217,93 & 30,00 & 77,09 & & 78,47 & 31,07 & 147,69 & 75,00 & & \\
\hline R22 & 439,94 & 95,09 & 414,26 & & & & 236,62 & & 238,56 & 31,60 & 304,96 & 77,00 & 413,62 & 77,00 \\
\hline R134a & 438,51 & 83,48 & 414,82 & & & & 241,72 & & 243,19 & 31,03 & 318,63 & 78,00 & 428,98 & 78,00 \\
\hline R227ea & 367,97 & 79,00 & 343,35 & & 352,71 & 40,25 & 234,64 & & 235,57 & 30,76 & 298,94 & 79,00 & & \\
\hline R161 & 638,80 & 89,89 & 591,91 & & & & 263,23 & & 266,12 & 31,10 & 377,72 & 77,00 & 600,49 & 77,00 \\
\hline R152a & 563,95 & 88,13 & 525,96 & & & & 252,80 & & 254,50 & 30,84 & 346,40 & 77,00 & 543,32 & 77,00 \\
\hline \multicolumn{15}{|c|}{ VARIANT II } \\
\hline R218 & 316,96 & 60,00 & 306,53 & \multirow{8}{*}{30,00} & 310,29 & 33,77 & 233,84 & \multirow{8}{*}{30,00} & 234,64 & 31,02 & 273,35 & 60,00 & & \\
\hline R32 & 557,19 & 108,83 & 515,72 & & & & 255,32 & & 259,39 & 33,00 & 400,38 & 78,00 & 428,90 & 78,00 \\
\hline R1234yf & 235,71 & 75,00 & 218,33 & & 217,93 & 30,00 & 77,09 & & 78,47 & 31,07 & 147,69 & 75,00 & & \\
\hline R22 & 444,73 & 108,76 & 414,26 & & & & 236,62 & & 239,19 & 32,15 & 324,77 & 87,00 & 406,07 & 87,00 \\
\hline R134a & 446,69 & 109,83 & 414,82 & & & & 241,72 & & 244,40 & 31,85 & 373,30 & 100,00 & 407,68 & 100,00 \\
\hline R227ea & 369,75 & 89,00 & 343,35 & & 352,36 & 39,87 & 234,64 & & 235,88 & 31,01 & 314,70 & 89,00 & & \\
\hline R161 & 651,64 & 109,15 & 591,91 & & & & 263,23 & & 267,62 & 31,64 & 426,03 & 92,00 & 582,75 & 92,00 \\
\hline R152a & 575,23 & 108,93 & 525,96 & & & & 252,80 & & 255,53 & 31,34 & 387,07 & 94,00 & 540,47 & 94,00 \\
\hline \multicolumn{15}{|c|}{ VARIANT III } \\
\hline R218 & 316,96 & 60,00 & 306,53 & \multirow{8}{*}{30,00} & 310,29 & 33,77 & 233,84 & \multirow{8}{*}{30,00} & 234,64 & 31,02 & 273,35 & 60,00 & & \\
\hline R32 & 557,19 & 108,83 & 515,72 & & & & 255,32 & & 259,39 & 33,00 & 400,38 & 78,00 & 428,90 & 78,00 \\
\hline R1234yf & 235,71 & 75,00 & 218,33 & & 217,93 & 30,00 & 77,09 & & 78,47 & 31,07 & 147,69 & 75,00 & & \\
\hline R22 & 442,36 & 101,93 & 414,26 & & & & 236,62 & & 238,86 & \begin{tabular}{|l|}
31,88 \\
\end{tabular} & 314,27 & 82,00 & 410,68 & 82,00 \\
\hline R134a & 440,49 & 89,35 & 414,82 & & & & 241,72 & & 243,43 & 31,20 & 328,21 & 83,00 & 428,30 & 83,00 \\
\hline R227ea & 369,62 & 87,00 & 343,35 & & 352,61 & 40,14 & 234,64 & & 235,82 & 30,96 & 311,38 & 87,00 & & \\
\hline R161 & 642,30 & 94,99 & 591,91 & & & & 263,23 & & 266,48 & 31,23 & 389,35 & 81,00 & 598,00 & 81,00 \\
\hline R152a & 566,71 & 93,01 & 525,96 & & & & 252,80 & & 254,72 & 30,95 & 355,43 & 81,00 & 543,42 & 81,00 \\
\hline
\end{tabular}

\section{Analysis of the calculation results}

Table 7 below shows the calculation results of the basic operating parameters of the ORC station, depending on the working medium and a heat source variant. As can be seen best results, regardless of the variant of a heat source used, were obtained for R227ea factor.

Table 7. Calculation results of the ORC station parameters depending on working medium and the heat source variant

\begin{tabular}{|c|c|c|c|c|c|c|c|c|c|}
\hline Medium & $\dot{\mathrm{m}}_{\mathrm{n}}$ & $\dot{\mathrm{Q}}_{\mathrm{W} 1}$ & $\dot{\mathrm{Q}}_{\mathrm{W} 2}$ & $\dot{\mathrm{Q}}_{\mathrm{W} 3}$ & $\dot{\mathrm{Q}}_{\text {wyp }}$ & $\mathrm{N}_{\mathrm{t}}$ & $\mathrm{N}_{\mathrm{p}}$ & $\mathrm{N}_{\mathrm{C}-\mathrm{R}}$ & $\eta$ \\
\hline & {$[\mathrm{kg} / \mathrm{s}]$} & {$[\mathrm{kW}]$} & {$[\mathrm{kW}]$} & {$[\mathrm{kW}]$} & {$[\mathrm{kW}]$} & {$[\mathrm{kW}]$} & {$[\mathrm{kW}]$} & {$[\mathrm{kW}]$} & {$[\%]$} \\
\hline \multicolumn{10}{|c|}{ VARIANT I } \\
\hline R218 & 8,38 & 324,46 & 365,54 & & 609,28 & 87,42 & 6,71 & 80,72 & 11,70 \\
\hline $\mathrm{R} 32$ & 2,32 & 326,67 & 66,08 & 297,25 & 603,34 & 96,09 & 9,43 & 86,66 & 12,56 \\
\hline R1234yf & 4,39 & 303,74 & 386,26 & & 619,80 & 76,27 & 6,07 & 70,20 & 10,17 \\
\hline R22 & 3,43 & 227,51 & 372,31 & 90,18 & 608,66 & 87,99 & 6,65 & 81,34 & 11,79 \\
\hline $\mathrm{R} 134 \mathrm{a}$ & 3,53 & 266,50 & 389,83 & 33,67 & 611,50 & 83,69 & 5,19 & 78,50 & 11,38 \\
\hline R227ea & 5,21 & 330,25 & 359,75 & & 566,54 & 128,31 & 4,85 & 123,46 & 17,89 \\
\hline R161 & 1,85 & 206,62 & 412,45 & 70,93 & \begin{tabular}{|l|}
608,54 \\
\end{tabular} & 86,81 & 5,35 & 81,46 & 11,81 \\
\hline R152a & 2,23 & 204,92 & 439,08 & 46,00 & 609,08 & 84,71 & 3,79 & 80,92 & 11,73 \\
\hline \multicolumn{10}{|c|}{ VARIANT II } \\
\hline R218 & 6,46 & 250,17 & 281,83 & & 469,77 & 67,40 & 5,17 & 62,23 & 11,70 \\
\hline R32 & 1,79 & 251,87 & 50,95 & 229,18 & 465,19 & 74,08 & 7,27 & 66,81 & 12,56 \\
\hline R1234yf & 3,38 & 234,19 & 297,81 & & \begin{tabular}{|l|}
477,88 \\
\end{tabular} & 58,80 & 4,68 & 54,12 & 10,17 \\
\hline R22 & 2,59 & 221,51 & 210,43 & 100,06 & 459,79 & 78,87 & 6,65 & 72,21 & 13,57 \\
\hline $\mathrm{R} 134 \mathrm{a}$ & 2,63 & 338,99 & 90,42 & 102,59 & 455,23 & 83,81 & 7,05 & 76,77 & 14,43 \\
\hline R227ea & 3,97 & 313,23 & 218,77 & & 432,01 & 104,91 & 4,93 & 99,99 & 18,79 \\
\hline R161 & 1,39 & 219,45 & 217,11 & 95,44 & 455,34 & 82,75 & 6,08 & 76,66 & 14,41 \\
\hline R152a & 1,66 & 218,89 & 255,27 & 57,84 & 454,55 & 81,99 & 4,54 & 77,45 & 14,56 \\
\hline \multicolumn{10}{|c|}{ VARIANT III } \\
\hline R218 & 14,84 & 574,63 & 647,37 & & 1079,05 & 154,83 & 11,88 & 142,95 & 11,70 \\
\hline $\mathrm{R} 32$ & 4,10 & 578,54 & 117,03 & 526,43 & 1068,53 & 170,17 & 16,70 & 153,47 & 12,56 \\
\hline R1234yf & 7,77 & 537,93 & 684,07 & & 1097,68 & 135,07 & 10,75 & 124,32 & 10,17 \\
\hline R22 & 6,00 & 452,83 & 578,93 & 190,24 & 1066,71 & 168,74 & 13,45 & 155,29 & 12,71 \\
\hline R134a & 6,20 & 525,73 & 620,67 & 75,59 & 1073,42 & 159,18 & 10,60 & 148,58 & 12,16 \\
\hline R227ea & 9,13 & 690,09 & 531,91 & & 992,85 & 239,92 & 10,78 & 229,15 & 18,75 \\
\hline R161 & 3,25 & 399,52 & 678,44 & 144,04 & 1068,72 & 163,85 & 10,57 & 153,28 & 12,54 \\
\hline R152a & 3,92 & 394,46 & 736,32 & 91,22 & 1069,91 & 159,61 & 7,52 & 152,09 & 12,45 \\
\hline
\end{tabular}


Figure 7 shows a comparison of the ORC capacity, depending on the working medium used and the variant of the station power supply. As can be seen, the best results were obtained for the R227ea medium and the best variant of using a heat source is variant III, that is as a result of supplying the steam generator of the ORC station with the engine cooling water further heated with exhaust gas energy.

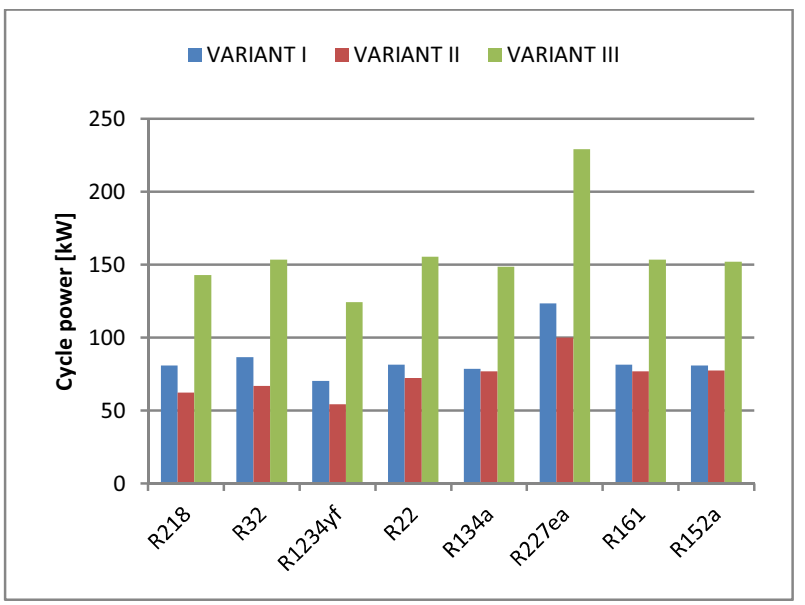

Fig. 7. Comparison of the ORC power system according to the variant of heat source and working medium used

Analyzing Figure 7 it can also be noted that the lowest power values of the station were obtained in variant II which is connected with the fact that the heat flux fed with the exhaust gas stream was much lower than in the case of variants I and III.

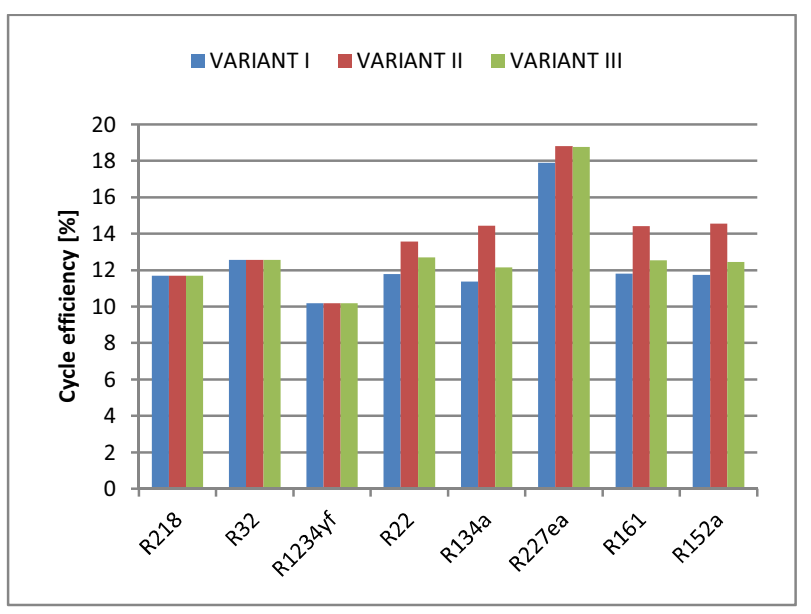

Fig. 8. Efficiency comparison of the ORC system according to the variant of heat source and working medium used

Figure 8 shows the comparison of efficiencies achieved by the ORC station, depending on the working medium and the variant of the station power supply.

In case of efficiency the highest values were obtained in variant II since in this variant it was possible to obtain the highest steam temperature of the organic medium at the inlet to the turbine.

Figure 9 shows a graph comparing the power of the ORC station in variant III and the total value of the station power of the other two variants. The graph shows that the common use of both waste heat streams produced in the engine to power the ORC station is in the case of three factors more advantageous or slightly lower for the other five working fluids than separable management of waste heat streams from the compression ignition engine in two separate ORC systems.

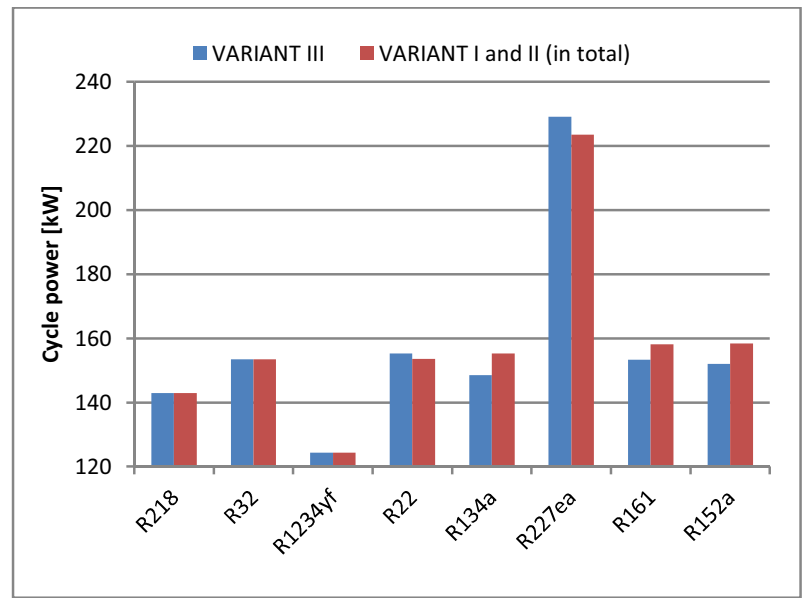

Fig. 9. Comparison of the ORC system power in variant III and power sums of the systems from variants I and II according to the working medium used. ।

Table 8 presents a summary on how the use of the ORC station to utilize the waste heat, which arises in the stationary compression ignition engine, affects the overall efficiency increase of the electric energy generation process by the generator set.

The highest power, as shown in Table 7, was obtained for R227ea medium in variant III, that is why the biggest increase in the overall efficiency of the generator set was noted exactly in the case of the station working with this medium, in variant III, and amounts $8,81 \%$, which reflects $22,58 \%$ increase of efficiency.

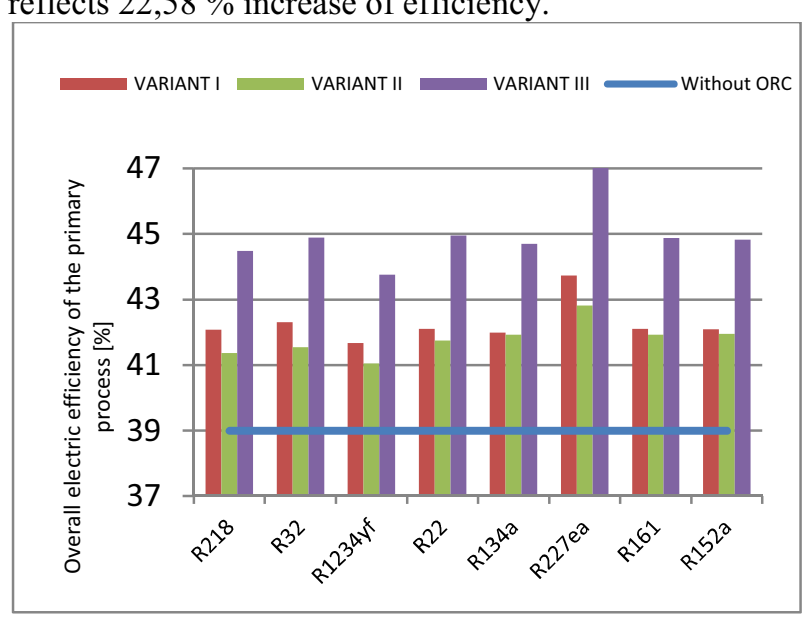

Fig. 10. Comparison of the generator set efficiency after using the ORC system with the primary efficiency

Figure 10 shows comparison of the overall electric efficiency of the generator set after using waste heat recovery through the ORC station, by anticipated variants of using this heat, and the primary efficiency (without using heat recovery) which in the case of this generator set amounts $39,0 \%$. 
Table 8. Efficiency increase of the generator set after the ORC system use for waste heat utilization.

\begin{tabular}{|c|c|c|c|c|c|c|c|}
\hline \multicolumn{8}{|c|}{ electrical efficiency of the generator plant } \\
\hline \multicolumn{2}{|r|}{ before } & \multicolumn{6}{|c|}{ after } \\
\hline power & efficiency & working fluid & ORC power & power in total & efficiency & \multicolumn{2}{|c|}{ efficiency increase } \\
\hline$[\mathrm{kW}]$ & {$[\%]$} & & {$[\mathrm{kW}]$} & {$[\mathrm{kW}]$} & {$[\%]$} & [point \%] & {$[\%]$} \\
\hline \multicolumn{8}{|c|}{ VARIANT I } \\
\hline \multirow{8}{*}{1010} & \multirow{8}{*}{39} & R218 & 80,72 & 1090,72 & 42,08 & 3,08 & 7,90 \\
\hline & & R32 & 86,66 & 1096,66 & 42,31 & 3,31 & 8,49 \\
\hline & & R1234yf & 70,20 & 1080,20 & 41,67 & 2,67 & 6,86 \\
\hline & & R22 & 81,34 & 1091,34 & 42,10 & 3,10 & 7,96 \\
\hline & & R134a & 78,50 & 1088,50 & 41,99 & 2,99 & 7,68 \\
\hline & & R227ea & 123,46 & 1133,46 & 43,73 & 4,73 & 12,13 \\
\hline & & R161 & 81,46 & 1091,46 & 42,11 & 3,11 & 7,97 \\
\hline & & R152a & 80,92 & 1090,92 & 42,09 & 3,09 & 7,92 \\
\hline \multicolumn{8}{|c|}{ VARIANT II } \\
\hline \multirow{8}{*}{1010} & \multirow{8}{*}{39} & R218 & 62,23 & 1072,23 & 41,37 & 2,37 & 6,07 \\
\hline & & R32 & 66,81 & 1076,81 & 41,54 & 2,54 & 6,52 \\
\hline & & R1234yf & 54,12 & 1064,12 & 41,05 & 2,05 & 5,27 \\
\hline & & R22 & 72,21 & 1082,21 & 41,75 & 2,75 & 7,06 \\
\hline & & R134a & 76,77 & 1086,77 & 41,93 & 2,93 & 7,51 \\
\hline & & R227ea & 99,99 & 1109,99 & 42,82 & 3,82 & 9,80 \\
\hline & & R161 & 76,66 & 1086,66 & 41,92 & 2,92 & 7,50 \\
\hline & & R152a & 77,45 & 1087,45 & 41,95 & 2,95 & 7,57 \\
\hline \multicolumn{8}{|c|}{ VARIANT III } \\
\hline \multirow{8}{*}{1010} & \multirow{8}{*}{39} & R218 & 142,95 & 1152,95 & 44,48 & 5,48 & 14,05 \\
\hline & & R32 & 153,47 & 1163,47 & 44,89 & 5,89 & 15,09 \\
\hline & & R1234yf & 124,32 & 1134,32 & 43,76 & 4,76 & 12,21 \\
\hline & & R22 & 155,29 & 1165,29 & 44,96 & 5,96 & 15,27 \\
\hline & & R134a & 148,58 & 1158,58 & 44,70 & 5,70 & 14,61 \\
\hline & & R227ea & 229,15 & 1239,15 & 47,81 & 8,81 & 22,58 \\
\hline & & R161 & 153,28 & 1163,28 & 44,88 & 5,88 & 15,08 \\
\hline & & R152a & 152,09 & 1162,09 & 44,83 & 5,83 & 14,96 \\
\hline
\end{tabular}

\section{Conclusion}

After the analysis presented in the work the following conclusions have been formulated:

recovery of waste heat through the ORC station can improve the electric efficiency of the generator set based on a compression ignition engine,

the best energy results are obtained by simultaneous use of both available waste heat streams which arise in a compression ignition engine, in a form of the engine cooling water jet and exhaust gas stream,

an important aspect of the effective use of waste heat through the ORC station is the proper selection of working medium. The most advantageous results were obtained for the ORC system with the use of R227ea working medium.

\section{References}

1. Decree of the Ministry of Economy dated 10 August 2012 on the specific scope and method of preparation of the energy efficiency audit, a card design of the energy efficiency audit and the methods for energy savings calculations.

2. A. Borsukiewicz-Gozdur, W. Nowak, Increasing of electricity generation capacity of biogas power generator by application of sub- and supercritical modules of Organic Rankine Cycle. Archives of
Thermodynamics, Vol. 30(2009), No. 4, pp. 175188.

3. R. Kaczmarek, Wykorzystanie ciepła powstającego w kogeneracji w silniku gazowym do zwiększenia produkcji energii elektrycznej, Energetyka 2013, nr 9, s. 664-668.

4. F. Ayachi, E. B. Ksayer, P. Neveu, A. Zoughaib, Experimental investigation and modeling of a hermetic scroll expander, Applied Energy, Vol. 181, 2016, pp. 256-267.

5. E. Galloni, G. Fontana, S. Staccone, Design and experimental analysis of a mini ORC (organic Rankine cycle) power plant based on R245fa working fluid, Energy 90, pp. 768-775.

6. E. W. Lemmon, M. L. Huber, and M. O. McLinden, Refprop, NIST Standard Reference Database 23, ver. 9.1, National Institute of Standards and Technology, USA. 